\title{
INTENTIONALISM AND THE ARGUMENT FROM NO COMMON CONTENT
}

\author{
Michael Tye \\ The University of Texas at Austin
}

Disjunctivists (Hinton 1973, Snowdon 1990, Martin 2002, 2006) often motivate their approach to perceptual experience by appealing in part to the claim that in cases of veridical perception the subject is directly in contact with the perceived object. When I perceive a table, for example, there is no table-like sense-impression that stands as an intermediary between the table and me. Nor am I related to the table as I am to a deer when I see its footprint in the snow. I do not experience the table by experiencing something else over and above the table and its facing surface. I see the facing surface of the table directly.

This, of course, is the view of naïve realism. And it seems as good a starting point as any for further theorizing about the nature of perception. Some disjunctivists have suggested that to do proper justice to the above thought, we need to suppose that the objects we perceive are components of the contents of our perceptual experiences in veridical cases. This supposition is supported further by the simple observation that if I see an object, it must look some way to me. But if an object looks some way to me, then intuitively it must be experienced as being some way. And how can the object be experienced as being some way unless the object itself figures in the content of the experience, assuming that experience is representational at all?

A third related consideration is that in cases of illusion, the perceived object appears other than it is. In such cases, intuitively, the perceptual experience is inaccurate. ${ }^{1}$ And it is so precisely because the object is not as it appears to be. This strongly suggests that, at least in those cases where there is a perceived object, a perceptual experience has a content into which the perceived object enters along with its apparent properties. ${ }^{2}$ The experience, then, is accurate if and only if the object has those apparent properties.

Once it is acknowledged that the content of visual experience is singular in veridical cases, it must also be acknowledged that in cases of hallucination, the content (if there is one) is not singular. ${ }^{3}$ For in these cases, there is no object with 
which the subject is in perceptual contact. This has led disjunctivists to conclude that there is no shared mental state common to veridical and hallucinatory visual experiences. ${ }^{4}$ The class of such experiences is not like the class of beliefs, say. Instead, the former class is more like the class of tables or tigers.

This is not to say that to their subjects veridical and hallucinatory experiences never seem the same. Upon occasion the former may be introspectively indistinguishable from the latter. But when this happens, the veridical experience and the hallucinatory experience are no more closely related than a lemon and a bar of soap that looks just like a lemon (Austin 1962). The one experience is indistinguishable from the other via introspection just as the lemon and the soap are indistinguishable from one another perceptually. Even so, the two are very different kinds of thing.

On the face of it, the above line of reasoning is a non sequitur. The fact that there is no common content does not entail that there is no common mental state; for experiences can be typed not only by their representational contents but also by their phenomenal character, by what it is like to undergo them. Why should not two experiences with different representational contents have the same phenomenal character? This is what happens, according to some philosophers, in the case of Inverted Earth (Block 1990). Why not hold that something of the same sort is going on in the case of the veridical perception of a tomato and the hallucinatory perception of one? After all, the obvious explanation of the fact that the experiences are introspectively indistinguishable in this case is that they have the same phenomenal character.

Perhaps this is too fast. Consider again the case of the lemon and the bar of soap. These two very different objects may nonetheless be visually indistinguishable. The best explanation of this fact, it could be urged, is not that the two items are intrinsically the same but rather that they produce experiences that cannot be told apart introspectively. ${ }^{5}$ On this view, the visual indistinguishability of the soap and the lemon is grounded upon a relational fact about them, the fact that they cause introspectively indistinguishable experiences.

Likewise, then, perhaps it can be denied that some veridical experiences and some hallucinatory ones have the same phenomenal character. What is really true is merely that these experiences sometimes have indistinguishable phenomenal characters, where this is to be understood in terms of their possession of a common relational property. Now there is no immediate difficulty in identifying phenomenal character with representational content.

The trouble with this retort is that there is no plausible candidate for the relevant relational property. The best alternative seems to be that both the phenomenal character of the veridical experience and the corresponding phenomenal character of the hallucinatory experience cause their subjects to believe, when they introspect, that the two experiences are exactly alike. But alike in which respect? Presumably, phenomenal character. The subjects of the relevant experiences are simply not conscious of any phenomenal difference via introspection. 
The question now becomes why they are not conscious of any such difference. Surely the most straightforward and natural answer is that in some cases there is no difference: the phenomenal character is the same.

What is striking about this reply to the disjunctivist is that it, together with what we might call "the disjunctivist's insight about content", can now be used to generate a simple argument against strong intentionalism with respect to the phenomenal character of experience. ${ }^{6}$ The argument goes as follows:

1). No veridical and hallucinatory experiences share the same representational content (disjunctivist's insight)

2). Some veridical and hallucinatory experiences have the same phenomenal character (best explanation of introspective indiscriminability in many cases).

So,

3) Phenomenal character is not the same as representational content.

Let us call this argument "the argument from no common content". One of the purposes of this article is to explore the options available to the intentionalist about phenomenal character (Byrne 2001, Dretske 1995, Jackson 2003, Lycan 1996, Tye 1995, 2000) in responding to this argument. Another more general purpose is that of illuminating the nature of perceptual content. A third purpose is to present a new proposal about the relationship of phenomenal character and representational content.

The article is divided into ten sections. In Section I, I discuss further the view, at odds with this introduction, that experiences have only existential contents, and I raise a further serious objection to it. In Section II, I consider the thesis that experiences have only singular contents in normal, veridical cases and gappy contents otherwise. Section III summarizes David Kaplan's view of indexicals. Section IV contains a quasi-intentionalist Kaplanian proposal about the nature of phenomenal character. Section V brings out a serious difficulty with this proposal. In Section VI, I elaborate the thesis that experiences have multiple contents. In Section VII, I consider an attempt to re-instate the existential thesis of Section I. Section VIII is devoted to still further discussion of the thesis that experiences have existential contents and some general conclusions are drawn about the argument from no common content. In Section VIV, I discuss a new proposal connecting phenomenal character and intentional content. Section $\mathrm{X}$ summarizes my conclusions.

\section{The Existential Thesis}

The thesis that experiences do not have singular contents into which their experienced objects enter is endorsed by Colin McGinn (1982) in the following passage: 
...the content of experience is not to be specified by using any terms that refer to the object of experience, on pain of denying that distinct objects can seem precisely the same... we are to say that a given experience is as of $a$ book that is brown, thick, and has the words 'The Bible' inscribed upon it; we are not to say, when giving the content of the experience which book it is that is seen. (p. 39)

Other philosophers who take a similar view include Lewis (1980) and Millar (1991).

In a later passage (p. 42), McGinn qualifies the above remarks by saying that the concepts used to characterize the content of visual experience should be restricted to concepts of "colour, superficial texture, shape, etc." Concepts such as the concept book, in his view, really only enter into associated beliefs.

It is clear that McGinn supposes that experiences can have the same content but different objects. What is not so clear is why he supposes this. He says above that to hold that particular objects enter into the content of experience is to be compelled to deny that distinct objects can seem precisely the same. ${ }^{7}$ This seems too hasty. Singular contents that include different experienced objects are certainly different contents, but why should this be taken to show that the way one object seems to a given perceiver cannot be precisely the same as the way another object seems? Perhaps McGinn's thought is that when the singular contents are different, the total 'seemings' cannot be the same. However, if one total 'seeming' is the same as another just in case the two experiences have the same phenomenal character, the fact that the two experiences have different singular contents clearly does not show that the total 'seemings' must be different. ${ }^{8}$

The positive thesis that experiences have only existential contents is embraced by Martin Davies (1992). If this thesis is correct, then it undercuts premise (1) of the argument from no common content; for there is now a common content shared by some veridical and hallucinatory experiences. Here is what Davies says:

... we can take perceptual content to be existentially quantified content. A visual experience may present the world as containing an object of a certain size and shape, in a certain direction, at a certain distance from the subject. (p. 26)

Davies' reason for adopting this view is essentially the same as the one McGinn offers for his position. One immediate objection, then, to the existential thesis is that, as yet, it lacks a clear motivation. For present purposes, I shall put this to one side. The objection to the existential thesis I want to develop in this section is that it yields an unequivocal result of veridicality in certain cases in which such a result is not warranted. Thus, the existential thesis should be rejected.

Suppose that I am looking directly ahead and that, unknown to me, there is a mirror in front of me placed at a 45 degree angle behind which there is a yellow cube. ${ }^{9}$ Off to the right of the mirror and reflected in it is a cube that is white in color. Through special lighting conditions, this cube appears yellow 
to me. According to the existential thesis, in these circumstances, my experience is accurate or veridical. It 'says' that there is a yellow cube located in front of me, and there is such a cube. But I do not see that cube. I see something else, something that does not have the properties in question. That cube looks to me other than it really is. My experience misrepresents its color. So, my visual experience cannot be counted as accurate simpliciter, as the existential thesis requires. It follows that the existential thesis should be rejected.

One way to try to defend the existential thesis against this objection is to make the existential content more elaborate. Thus, it might be held that my experience represents that there is a yellow cube that stands in such-andsuch a causal/contextual relation to this very experience, where the relevant causal/contextual relation is the one needed for seeing the relevant cube. ${ }^{10}$ Now my experience is inaccurate, since the object causing it is not yellow.

This proposal does not do full justice to the thought that the cube I see looks to me other than it is. Intuitively, I misperceive that cube. My experience misrepresents $i t$. This is possible only if the cube I see is itself a component of the content of my experience. Furthermore, the proposal that experiences, in part, refer to themselves is not easy to swallow. Intuitively, when I see a tomato, for example, my visual experience is directed upon the tomato. It is not about itself in addition to the tomato.

A third difficulty is that if deviant causal chain counter-examples are to be avoided, it will have to be stipulated that the relevant causal chain is not deviant. But the conditions needed to spell out non-deviance are surely not ones that are perceptually available.

A fourth problem can be brought out by considering the case of memory. For me to remember that $p$, there must be a causal connection between the historical event that makes ' $p$ ' true and my current memory state, or so it is usually supposed. But patently, that causal connection is not part of the content of the memory. To think otherwise is to confuse the satisfaction conditions for ' $X$ remembers that $p$ ' with those for ' $p$ '. It is also standardly held that truly believing that $p$ is not enough for knowing that $p$. In addition, the belief must be appropriately caused. This fits with the causal requirement on memory, given that memory is a species of knowledge. But again, it would clearly be silly to hold that the relevant causal connection must be in the known content. That isn't what is known though its existence is a necessary condition of the subjects' knowing what she knows. Correspondingly, in the case of perception and perceptual experience. ${ }^{11}$

Finally, the proposal is ad hoc. To see this, consider the case of a police radar gun $R$. Trained on Claude's Ferrari, it represents that it is going $90 \mathrm{mph}$. But the gun does not represent that it is Claude's Ferrari upon which it is trained. $R$ 's reading represents the speed of Claude's Ferrari via a certain causal, contextual relation which connects the two. It is the existence of this relation which determines that $R$ is then representing Claude's Ferrari and not Paul's Porsche. The relation $R$ 's reading bears to the Ferrari and the speed $R$ registers is 
why Claude gets the speeding ticket and not Paul. But the relation itself is surely not part of the content of $R$ 's reading. The reading does not 'say' that there is a car owned by Claude that bears the appropriate relation to that very reading.

There is no clear reason to treat the case of visual experiences any differently. What makes it the case that my veridical experience of a tomato is about one particular tomato is not how that tomato is represented by my experience but rather a certain causal/contextual relation the experience bears to that tomato. This causal/contextual relation is not itself part of the content of my experience any more than the causal/contextual relation the radar gun reading bears to the speed of Claude's car is part of the content of that reading. ${ }^{12,13}$

The upshot is that the existential thesis is in trouble. Appealing to that thesis does not provide the strong intentionalist with a satisfactory way of responding to the argument from no common content.

\section{The Singular (When Filled) Thesis}

Consider the china frog that is sitting by one of my house-plants. As I view it, I think to myself that that is a china frog. A little later, I look up from the book I am reading and again I think to myself that that is a china frog. Unknown to me, a mischievous demon has made the frog disappear in the intervening time period while still making it appear to me that the frog is present. In the second case, then, there is no frog for my thought to be about. Even so, in the second case, I did think something, just as I did in the first. According to one standard use of the term 'content', what I thought was the content of my thought. So, in the second case, my thought has a content just as in the first.

My first thought, as I looked at the china frog, had a singular content, into which the china frog entered. The second thought did not have a singular content, at least on the usual use of the term 'singular content'. How, then, are we to conceive of the content of the second thought?

The natural proposal, I suggest, is that the second content is just like the first except that where the first has a concrete object in it, the second has a gap. The two contents, thus, have a common structure. This structure may be conceived of as having a slot in it for an object. In the case of the first content, the slot is filled by the china frog. In the case of the second content, the slot is empty. I shall such structures "content schemas."

Some may be disinclined to count the second content as a content at all. But, as noted above, I am certainly thinking something in the above case. ${ }^{14}$ Furthermore, there are other, independently plausible examples of thoughts with gappy contents. Consider, for example, the thought that Vulcan does not exist. Here, what is thought is true. But with the demise of descriptivist theories of proper names, arguably the best account of the content of this thought is that it is gappy.

Returning now to the first thought that that is a china frog. This thought is true: the object in the content has the property in it. What of the second thought? 
Well, the second thought that that is a china frog is true if and only if that is a china frog. Since there is no object picked out by the demonstrative 'that' on the right hand side of this bi-conditional, there is no demonstrated object to have the property of being a china frog. So, the sentence on the right hand side of the bi-conditional is naturally classified as false. Correspondingly, then, given the truth of the bi-conditional, the thought is naturally classified as false too. ${ }^{15}$

Hereafter, I shall call content schemas of the above sort " $S W F$ content schemas" (schemas yielding singular contents when their slots are filled). With the failure of the existential thesis, it might now be suggested that the general line sketched above for singular (or putatively singular) thoughts can be applied to perceptual experiences. ${ }^{16}$ I want next to develop this suggestion further.

Whether one is undergoing a veridical perceptual experience, an illusory experience or an hallucinatory one, one experiences something. One's experience has a content, or so it seems very reasonable to suppose. The singular (when filled) thesis, as I shall call it, holds that in the case that a visual experience is veridical it has a content that is an instance of an $S W F$ content schema, the slot in which is filled by the seen object, where the properties attributed in the content are properties the seen object has. ${ }^{17}$ In the case that an illusion is present, the experience again has a content that is an instance of an $S W F$ content schema, the slot in which is filled by the seen object, but now the seen object lacks one or more of the properties attributed in the content. In the case of an hallucination, the experience has a content that is an instance of an $S W F$ content schema, the slot in which is empty. ${ }^{18}$

One way to conceive of the relevant $S W F$ schemas is on the model of Russellian singular propositions having slots in place of objects. When the slot is filled by a seen object, a Russellian singular proposition results. In other cases, when the slot is empty, there is a gappy proposition. This, of course, is not the only way to view the $S W F$ schemas. ${ }^{19}$

With these points about content schemas in hand, let us now return to the argument from no common content with which we began. That argument went as follows:

1) No veridical and hallucinatory experiences share the same representational content.

2) Some veridical and hallucinatory experiences have the same phenomenal character.

So,

3) Phenomenal character is not the same as representational content.

If the singular (when filled) thesis is true, then premise (1) of this argument is true and strong intentionalism is refuted. But is the singular (when filled) thesis true? 
Consider again the mirror case from the last section. The present thesis yields the unequivocal result that my visual experience is inaccurate, since the cube I am seeing enters into the content of my experience as does the color property it appears to have, and the latter is a property it actually lacks. But this does not seem the right thing to say. After all, it certainly appears to me that there is a yellow cube in front of me; and there is such a cube. The world is as it appears in this respect.

A further case, which presents trouble for the singular (when filled) thesis, is this. In front of me, there is a blue, bouncing ball. Unknown to me, the information in the light reflected from the ball and reaching my retina is not processed any further. An evil neuroscientist has blocked the signals from my retina to my optic nerve while simultaneously and serendipitously activating my visual cortex by means of electrical probes in just the way it would have been activated had the signals got through. In these circumstances, I do not see the bouncing ball. There is no item out there in the world in front of me that causes my visual experience. Nor do I misperceive the bouncing ball for the same reason. I am not subject to an illusory experience. The experience I undergo is hallucinatory. I hallucinate a blue, round, bouncing object before me. Even so, my experience is accurate. The world is just as it appears to me. I am undergoing a veridical hallucination.

The singular (when filled) thesis apparently cannot accommodate cases of veridical hallucination. ${ }^{20}$ According to that thesis, where there is no seen object, the visual experience has a gappy content; and the gappy content is false, or at least neither true nor false.

Note that once veridical hallucinations are admitted, premise (1) of the argument from no common content is clearly false, since the experiences that occur in such hallucinations are both veridical and hallucinatory. But this does not remove the threat the argument poses to intentionalism, since the premise can easily be restated as

( $\left.1^{\prime}\right)$ No veridical experiences share the same content as any non-veridical hallucinatory experiences.

Now with a corresponding restatement of premise (2), the argument still has not been answered.

I want next to consider a thesis according to which not all perceptual experiences have content. This thesis obviously is not one that can be appealed to by the strong intentionalist; but, as we shall see, it is compatible with weak intentionalism and it does purport to provide a substantive account of the nature of phenomenal character that is at least of a quasi-intentional sort. The thesis requires some stage-setting. It is to this stage setting-in particular, to a brief presentation of Kaplan's theory of indexicals - that the next section is devoted. 


\section{Kaplan on Indexicals}

Indexicals are terms that change their reference from utterance to utterance. Examples are 'I', 'here', 'she', 'that', 'today' and 'here'.

Consider the following two utterances:

Tim: "I am hot".

Tom: "I am hot".

Intuitively, these two utterances have the same linguistic meaning, but what Tim says is different from what Tom says. Tim, who is cold (let us suppose) says something false; but Tom (who is hot) says something true. So, the content of Tim's remark is different from the content of Tom's.

On Kaplan's theory (1989), indexicals have contents with respect to contexts. For example, the content of 'I' with respect to a given context $C$ is the subject or agent of $C$; the content of 'that' with respect to $C$ is the object demonstrated in $C$; the content of 'here' with respect to $C$ is the location of $C$. The content of a sentence containing an indexical is a structured proposition having as its constituents the content of the indexical (the agent, place, object demonstrated, etc) and the contents of the other terms, where these contents are taken to be worldly entities: particulars, properties and relations. Thus, in the case of Tim's utterance of the sentence "I am hot," the content of Tim's remark is a structured proposition containing Tim himself (the subject in this context) and the property of being hot (the content of the predicate 'is hot'). The sentence is false in the context, given that Tim is cold.

On Kaplan's theory, the linguistic meaning of an indexical term is a function that maps contexts onto contents, where the latter are those contents the term has at each context. Kaplan calls this function the term's character. Thus, consider the term 'here'. Its character is a function from contexts whose value at each context is the location of that context. Similarly, the character of the term 'that' is a function from contexts to the objects demonstrated in those contexts. In the case of sentences containing indexicals, their characters are functions from contexts to the structured propositions that are the contents of the sentences in those contexts.

One case not explicitly discussed by Kaplan that is relevant to the theory in the next section is that of demonstratives used in failed demonstrations. Suppose, for example, I mistakenly think that I have demonstrated something and that I have used the term 'that' to refer to it. In reality, there is nothing to be demonstrated, no referent for my utterance of 'that'. The content of the term 'that' in any given context, on Kaplan's theory, is the object demonstrated in that context. But what counts as a context here?

Each context has associated with it at least an agent or subject, a time, and a location. In the case of 'that', it seems plausible to hold that each context is a context of demonstration and thus that it also has associated with it a 
demonstrated object. So, where there is no demonstrated object, there is no context.

It follows that, in the case of a failed demonstration, the term 'that' has no content. It does, however, have a linguistic meaning. This is a function that maps contexts (of demonstration) onto the objects demonstrated in those contexts.

The above way of using the term 'content' does not fit well with the use of the term 'content' in my discussion of the singular (when filled) thesis in Section II. There it was held that when one has a demonstrative thought for which there is no object, nonetheless one's thought has content. Admittedly, there is no inconsistency in saying that in the case of a failed linguistic demonstration, one is expressing a thought that does have content. But if one says this, it is hard to see why one would not then be prepared to grant that the sentence one utters has content too. In any event, for the purposes of developing the Kaplanian proposal, in the next two sections I shall use the term 'content' in the more restricted way adopted in my presentation of Kaplan's theory.

We are now ready to turn to the case of perceptual content and phenomenal character.

\section{Kaplanianism about Phenomenal Character: The Proposal}

Strong intentionalism or representationalism is the view that phenomenal character is one and the same as a certain sort of representational content. Weak intentionalism, unlike strong intentionalism, is not an identity thesis. It does not purport to identify phenomenal character with representational content. It is rather a supervenience thesis. It asserts that necessarily experiences with the same representational content have the same phenomenal character. This thesis is untouched by the earlier argument from no common content. However, on its own, it offers no real illumination about the nature of phenomenal character.

I want in this section, to explore an alternative to the strong intentionalist thesis that models phenomenal character on Kaplanian character and that, in so doing, purports to offer a substantive account of the nature of phenomenal character which, if not fully within the intentionalist camp, is certainly in the general neighborhood. Let me begin my development of this alternative by saying a little more about the case of illusion.

Here there is a seen object. That object appears other than it is. The natural further account of this is that the subject's experience represents the object as having some property that it lacks. The case is one of misrepresentation. Thus, when I see a straight stick in water, and it appears bent to me, my experience represents it - the seen object - as bent. The difference between this case and the veridical one is not that in the latter I am in direct contact with an object whereas in the former I am not, but rather that the singular content into which the seen object enters is accurate in the latter case but not in the former. 
Now if it is indeed the case that veridical and illusory perceptual experiences have singular contents, then one possible view to take of cases of hallucination is that their phenomenology is misleading. It is for the subject of an hallucination as if the experience has a singular content, but in reality there is no content there at all. Thus, hallucinations are like cases of failed demonstration. Just as a token of 'this', uttered in a failed demonstration, has a linguistic meaning but no content, so a token experience, occurring in an hallucination, has a phenomenal character but no content.

This parallelism suggests that we might plausibly take phenomenal character to be modeled on Kaplanian character. In particular, we might take phenomenal character to be a function on contexts of experiential contact whose value at each context is a singular content that meets certain further conditions (for example, that is nonconceptual and suitably poised to bring about cognitive responses ${ }^{21}$ ). Such a view I call "Kaplanianism" about phenomenal character.

The relevant model for contexts of experiential contact is that of demonstratives. For tokens of 'that', a context, I suggested in the last section, is a context of demonstration. Thus, where there is no object demonstrated, there is no context in the relevant sense. In the case of perceptual experience, what experiences fundamentally aim to do is to put us in contact with objects around us. Where there is no object, as in the case of hallucination, there is no contact and so no context of experiential contact. The experience is a failed experience.

On this theory, each token experience has a phenomenal character, but not every token experience has a representational content. However, each token experience is a token of an experiential type for which there is a function having as its arguments contexts of experiential contact in which tokens of that type occur and having as its values the appropriate singular contents of those tokens. Again, the model is that of demonstratives. Each token of 'that' is a token of a linguistic type for which there is a function having as its arguments contexts of demonstration in which tokens of that type occur and having as its values the objects demonstrated via the use of those tokens.

\section{The Problem with Kaplanianism}

The main worry with the above proposal is that it is circular. Phenomenal character is identified with a certain function, the specification of which adverts to an experience type. But the relevant experience type, it seems, is itself phenomenal.

An initial reaction may be that this worry can be overcome. Consider the intentionalist claim that what it is for a token experience to have phenomenal character, $P$, is for it to have a representational content that meets certain further conditions. Some intentionalists (e.g., Tye 1995) conjoin this claim with the further claim that what is it for a token experience, $t$, to have a given content is for $t$ to belong to the type of experience that causally co-varies with the occurrence 
of the appropriate external state of affairs under optimal conditions. ${ }^{22}$ Patently, if it is now said that the type of experience that so co-varies is a phenomenal type, we have a small circle.

The obvious way to handle this problem is to say that $t$ occurs in a particular subject, $S$, and that, in $S, t$ has some property, $Q$, for example a neurological property, the tokening of which in $S$ causally co-varies with the occurrence of soand-so state of affairs under optimal conditions. Correspondingly, the Kaplanian can hold that what it is for a token experience, $t$, to have phenomenal character $P$ is for $t$ to have some property, $Q$, and for there to be some function, $F$, such that $F$ has as its value in each context, $C$, of experiential contact involving the subject of $t$, the relevant singular content of the token of $Q$ in $C$. Now the circularity disappears.

This is too fast, however. Consider, for example, the case of my hallucinating a ripe tomato. My token experience, $t$, has a range of properties, some functional, some neurological, some chemical, some microphysical. Which of these properties is the relevant property as far as the function goes? Suppose we choose a certain chemical property. There seems no obvious reason why that chemical property of $t$ could not be tokened in me in any number of very different veridical perceptual contexts involving experiences with singular contents into which very different objects enter. However, the phenomenal character in these contexts will vary. Furthermore, to make matters worse, for other properties of my experience, the function could take on different values in the same contexts. So, the function is not well defined.

The only way I see out of this problem is to say that the relevant property as far as defining the function is the phenomenal character of the experience. But this then re-introduces the original circularity. We are left, thus, without any substantive account of the nature of phenomenal character. The attempt to stake out a defensible position in the neighborhood of intentionalism has failed.

\section{The Multiple Contents Thesis}

So far it has been assumed that each perceptual experience has (at most) a single content. It is this assumption that the multiple contents thesis challenges. Furthermore, it is this assumption that intentionalists often reject. This needs some explanation.

On the one hand, intentionalists typically accept the view of naïve realists that perception involves direct contact with external things in standard, veridical cases. In those cases, the objects seen are just as they appear. Intentionalists often account for this fact by holding that perceptual experiences in such cases have accurate singular contents into which the seen objects enter. On the other hand, intentionalists have found much to agree with in the sense-datum theory. For example, they concur with the view of sense-datum theorists such as G.E. Moore (1903) that when we introspect, the qualities of which we are aware are 
external ones such as colors and shapes. The mistake of the sense-datum theorists, by the intentionalists' lights, was to hold that when something $O$ appears $F$, something other than $O$ - an appearance $O$ presents - is $F$. The truth in such a case, according to the standard intentionalist view, is not that there is something, besides $O$, that is $F$, but rather that the visual experience $O$ elicits represents (among other things) that there is an $F$.

Thus, consider the tomato again. Here is what H.H. Price said (1932) about the visual perception of a tomato in a famous passage at the beginning of his book Perception:

When I see a tomato there is much that I can doubt. I can doubt whether it is a tomato that I am seeing, and not a cleverly painted piece of wax. I can doubt whether there is a material thing there at all... One thing however I cannot doubt: that there exists a red patch of a round and somewhat bulgy shape, standing out from a background of other colour-patches, and having a certain visual depth, and that this whole field of colour is presented to my consciousness. (p. 3)

Intentionalists have not shared Price's certainty. In their view, it would have been much more plausible for Price to say merely that he could not doubt that it appeared to him that there was a red, round and somewhat bulgy shape. And the usual intentionalist explanation of this fact about appearing is that Price's experience represented that there was such a shape. It did so accurately in the veridical case and inaccurately in the illusory and standard, hallucinatory ones.

So, experiences have a layer of content that is existential, according to most intentionalists. This layer is to be found in all perceptual experiences, accurate or not, whereas singular contents are missing in some perceptual experiences (namely, the hallucinatory ones). Singular contents, thus, are not essential to perceptual experiences, whereas existential contents are. It is the layer of existential content that provides the common factor for veridical and hallucinatory experiences. And it is this layer of content that is responsible for the phenomenal character of perceptual experience. Premise (1) of the argument from no common content is, therefore, the premise that most intentionalists would reject.

Intentionalists who take this view also typically hold that the common content is tremendously rich and complex, involving many details that cannot be captured in concepts possessed by the subject of the experience (Dretske 1995, Tye 2000). Such content is standardly classified as nonconceptual. It is furthermore so situated in the stream of information processing that it stands ready and available (or poised) to make a difference with respect to what is believed (Tye 1995, 2000). Thus, poised, nonconceptual existential content is supposedly the common thread that runs through all perceptual experiences.

This position has no difficulty either with the mirror case of Section I or with the case of veridical hallucination. In the mirror case, my visual experience 
is accurate with respect to its existential content and inaccurate with respect to its singular content. It appears to me that there is before me an object of a certain shape and size and color at a certain distance away and in a certain direction and, as it happens, there is an object with the relevant apparent features, namely the yellow cube hidden behind the mirror. So, my experience has an accurate existential content. However, the cube I am actually seeing is not as it appears to be. It is white rather than yellow, as I am led to suppose on the basis of my experience. So, my experience has an inaccurate singular content.

In the case of a veridical hallucination, the subject undergoes an experience with an accurate existential content. The world appears to contain a blue, round, bouncing object before the subject, for example, and there is such an object. But the subject does not see the object. She is hallucinating. So, there is no singular content.

One interesting question is whether the multiple contents theorist needs to acknowledge a gappy $S W F$ content in addition to an existential content in the case of hallucinatory experiences. One argument for this view is that we need to suppose that there is a gappy $S W F$ content for such experiences in order to explain the deceptive nature of hallucinations and further to explain the actions hallucinations generate. Suppose, for example, that Sebastian hallucinates a large, furry spider crawling up his leg. He forms the belief that that spider is dangerous. In great fear, he reaches for a nearby book to hit it. That is why he reaches for the book. ${ }^{23}$

The general point that hallucinations are deceptive seems to me unpersuasive; for if hallucinatory experiences have existential contents then they have false contents (leaving aside those experiences occurring in veridical hallucinations). Unsurprisingly, then, they give rise to false beliefs and thus they deceive their subjects. They are also failed experiences in that they do not succeed in putting their subjects in contact with things in the world even though their subjects typically suppose otherwise.

However, it is true that the supposition that some experiences have gappy $S W F$ contents provides a straightforward explanation of the action performed by the victim of the hallucination. Consider again Sebastian. It is the spider he is hallucinating that he intends to squash with a book. He reaches for a book with the aim of killing that spider, and not the much smaller, innocuous looking spider on the ground to his left. Sebastian did not want to kill $a$ spider. He wanted to kill one particular spider-the spider that, according to his hallucination, was on his leg.

Still, this consideration seems to me indecisive. Suppose I say to you that Winston believes that there is a burglar in the house. I may then continue by remarking that Winston wants to find him and shoot him. That's why he is going upstairs with a gun in his hand. Clearly, the use of the pronoun 'him' here does not show that the content of Winston's belief is singular. What Winston believes has an existential content. Why not suppose something of the same sort is going in Sebastian's case? On this view, it is perfectly acceptable to say both 
that Sebastian has a visual experience of $a$ spider on his leg and that he wants to kill it.

Perhaps it will be replied that even if the example does not tell definitely in favor of the admission of gappy contents, it is nonetheless the case that the supposition that there is gappy content in hallucinatory cases preserves as much similarity as can be preserved between those cases and the veridical ones. So, given the overall introspective similarity between the two sets of cases, this is a point in favor of the view that some visual experiences have gappy contents.

We shall return to the question of whether gappy contents are needed in an account of the contents of visual experience in the next section. For the moment, it suffices to note that appealing to the thesis of multiple contents appears to give the intentionalist an adequate response to the argument from no common content. Appearances can be deceptive, however, as we shall shortly see.

\section{The Existential Thesis Revisited}

In the introduction to this article, I noted that adherence to naïve realism requires us to accept that we see the facing surfaces of common or garden material objects directly. The first point I want to make in this section is that granting this point about what is directly seen does not necessitate that we also accept that ordinary objects enter into the contents of our experiences. Indeed, consistent with this point, we could even deny that perceptual experiences have contents (as, for example, adverbial theorists do). What most strongly motivates the view that perceptual experiences have singular contents into which the seen objects enter is the thought that in seeing those objects, they look some way to us together with the further thought that an object can only look a certain way, if it is experienced as being that way. This in turn, seems to require that the object be represented as being that way. In the case of an illusion, then, there is misrepresentation since the seen object is not as it is represented as being. Here the seen object looks other than it is.

One possible response to this line of reasoning, consistent with the general view that experiences have representational contents, is to grant that one sees an object just in case it looks some way to one but to deny that the object's looking some way demands that one undergo an experience that represents it as being that way. Thus, one might hold that what it is for an object to look $F$ is for it to cause (in the distinctive way appropriate to seeing) an experience of an $F$, where the experience so caused has an existential content. If this response is cogent, ${ }^{24}$ then the existential theorist has a way of handling the mirror case discussed earlier. For she can say that while it is true that the subject misperceives the white cube on the right, this is because the cube the subject sees looks yellow and straight ahead, and its so looking requires only that it cause (in the right way) an experience that represents that there is a yellow cube ahead. So, the content is accurate even though the case is one of misperception. What we have here, the 
existential content theorist may say, is a case of veridical illusion. The case, thus, is a counterpart to the earlier case of veridical hallucination. The latter case did not demand an inaccurate or falsidical content, so why suppose the former does?

Here is an answer. Consider again Sebastian who is hallucinating a spider crawling up his leg. He tries to grab it. Now suppose that Sebastian's hallucination is veridical: there really is a spider crawling up his leg so that what Sebastian succeeds in grabbing is the real spider. Did Sebastian manage to grab the spider he was hallucinating? It seems not, for that spider is unreal. Nonetheless, that is the spider he tried to grab-the one that, according to his hallucination, was on his leg. To explain what Sebastian was trying to do in this case and further his failure to do it, it seems that we really must suppose that his experience has a gappy content, one with a quasi-singular character. That content is inaccurate or falsidical. At any rate, it is not accurate. So the claim that cases of veridical hallucination do not demand inaccurate or falsidical contents is mistaken.

Again, however, the existential theorist has a reply. Consider the case of Winston. He believes that there is a burglar upstairs. He is trying to catch him. That seems a perfectly good explanation of why Winston is running up the stairs, gun in hand, even if it turns out that there is no burglar. But Winston's belief certainly does not have a gappy content.

Now admittedly, in the case of veridical illusions, some of the beliefs formed directly on the basis of experience are singular. For example, in the mirror case, I believe falsely that that cube is yellow, where that cube is the one I am seeing located off to the right. The most straightforward account of the formation of beliefs with singular contents in such cases, it might be insisted, is that the experiences have singular contents too.

Once again, this point does not refute the existential theory. Consider Winston once again. Winston believes that there is a burglar upstairs. Given the direction of the noise, Winston forms the belief that he is in the red room. Even so, Winston's initial belief has an existential content.

It seems, then, that the above considerations do not refute the view that visual experiences have existential contents. The point I wish to establish next is that even if there are such existential contents, they are not pure (that is, without any constituent particulars).

Suppose that I am seeing a tomato at $2 \mathrm{pm}$ and then I close my eyes for ten seconds after which I view it again. How is this to be captured in terms of existential content? The obvious answer is that in both cases, my experience represents that there is something red, round and bulgy. But this won't do. For suppose that at $2 \mathrm{pm}$ there was something red, round and bulgy before me whereas at 2:00:10pm there is nothing red, round and bulgy in the world at all, nothwithstanding how thing then seem to me. In this case, intuitively, my later experience is inaccurate. However, its existential content is correct (on the assumption that 'there is' is tenseless).

The obvious response to this difficulty is to say that my experience at $2 \mathrm{pm}$ represents that there is something red, round and bulgy at $2 \mathrm{pm}$, whereas my 
experience at 2:00:10pm represents that there is something red, round and bulgy at the later time. The difficulty now is that the existential content of my experience at $2 \mathrm{pm}$ is no longer pure: it includes a particular time.

One way around this problem is to say that the relevant existential content is that there is presently something red, round and bulgy. The question now becomes how to understand 'presently'. If 'presently' means at the present time, that is, at the time of occurrence of the relevant token experience, then the above difficulty recurs. For in the case of the experience at $2 \mathrm{pm}$, the content involves a different token experience from the content of the experience at 2:00:10pm. Let us suppose then that 'presently' picks out a way or mode of being. If clear sense can be made of this, then the immediate difficulty dissolves.

Another difficulty is not far behind, however. Suppose that there is presently something red, round, and bulgy in front of a perceiver in Lithuania even though there is nothing red, round and bulgy anywhere else. Intuitively, my visual experience of a tomato, occurring in Texas, is inaccurate. Unfortunately, its existential content is accurate, if we suppose that its content is just that there is something red, round and bulgy. It is also accurate if we suppose that the content is that there is presently something red, round and bulgy in front of some perceiver.

There may be some who would be inclined to bite the bullet here and allow that experiences need not have the same accuracy or correctness conditions as their contents. But those who value their teeth should pause. After all, if what you believe is true, then your belief is true. Why should the situation be any different for experiences? Furthermore, on a causal co-variational account of experiential representation, if the content of my experience, as I view the tomato, is (simply) that there is presently something red, round and bulgy then my experience is of the type that, under Normal conditions, is tokened if and only if and because there is presently something red, round and bulgy. But patently, no visual experience is of this type; to suppose otherwise is like supposing that the height of a mercury column in a thermometer Normally tracks the temperature of air somewhere or other rather than the temperature of the surrounding air.

One simple way to handle the above difficulty is to introduce the subject of the experience into the content. What my experience at $2 \mathrm{pm}$ represents is that there is presently something red, round and bulgy in front of me. But again the existential content is not pure: the subject of the experience now enters into it.

It does not help, of course, to remove the subject from the content and replace him or her with an objective place; for again the existential content is not pure. Likewise if we say that the relevant existential content is one that brings in a causal relationship with the appropriate token experience, even setting to one side the earlier objections to this proposal.

The conclusion I draw is that if it is supposed that visual experiences have existential contents, these contents had better be partly singular. ${ }^{25}$ The seen object does not itself enter into the content, but other objects do-such objects as particular times or particular places or subjects of experiences or particular 
experiences themselves. This does not refute the existential view, of course, but it does naturally lead us to ask why once some singularity is admitted, it is necessary to insist, as the existential theorist does, that the seen object in particular does not enter into the relevant content.

I want next to respond to this question by arguing for the stronger conclusion that even with the introduction of impure existential contents, there is no good reason to suppose that any such contents attach to visual experiences. This counts against both the existential thesis and the multiple contents thesis; and it leaves the strong intentionalist without a rejoinder to the argument from no common content.

\section{Still More on Existential Contents}

Earlier it was urged against the Singular (When Filled) Thesis that it must at least be admitted that there is a layer of existential content in order to account for cases of veridical hallucination. The thought was that without such a layer of content, we cannot understand how it can be true that it appears to me that there is something blue, round, and bouncing ahead (or before me) in the case that there is such an object even though I am not seeing it.

I want now to suggest that there is another explanation available: my visual experience has a gappy content - a content with a gap in it where a seen object should go along with such properties as blueness, roundness and bounciness. But this gappy content disposes me to believe that there is something blue, round and bouncing. This is what makes it the case that it appears to me that there is something blue, round, and bouncing. Cases of veridical hallucination are veridical, then, only to the following extent: the visual experiences they involve dispose their subjects to form true beliefs. The experiences themselves, however, are falsidical or at least neither true nor false.

Note that this proposal does not entail that when it appears to me that $P, \mathrm{I}$ do actually believe that $P$. Evidently that would be too strong. In the case of the Muller-Lyer, for example, it appears to me that the lines are of different lengths but I do not believe it. Still I am disposed to believe this if I go by the content of my experience alone. Note further that the proposal does not assume any specific account of how the relevant disposition is to be cashed out. Consistent with this proposal, it could be denied that there is any straightforward further analysis of the relevant disposition. And certainly there is reason to resist any account of the disposition in simple if-then terms, as is shown by counter-examples of the sort proposed by C.B. Martin (1994) to straightforward if-then analyses of dispositions.

Another virtue of the above proposal is that it allows it to be true that, say, it visually appears to me that there are more than three red objects before me, that there are less than one hundred such objects, that there are more than seven red objects before me, less than three hundred, that there are at least twice as many 
red objects as green ones, and so on indefinitely even though I am not subject to any occurrent thought with any of these contents. Nor in this case need any of the given contents attach to my visual experience. I need not see the scene before me as having more than three red objects, etc. in order for it to visually appear to me that it is so. It suffices that my visual experience have a content that disposes me to believe that there are more than three red objects before me, less than one hundred, and so on, if I go by the content of the experience alone. The relevant contents, thus, are potential cognitive contents and not actual visual contents of my experience. And what goes for these contents is plausibly held to go for all contents expressible via sentence of the form "It visually appears to me that $P$."

So, where does this leave us? Even though no knockdown argument has emerged yet against the view that visual experiences have existential contents, there is no clear reason left to accept the view. Neither veridical hallucinations nor veridical illusions provide any strong support. Admittedly, McGinn, in the passage quoted at the beginning, did offer an additional reason, namely that we must suppose that the seen object does not enter into the content of experience "on pain of denying that seen objects can seem precisely the same." And this reason has not yet been discussed; but patently it is not compelling. Different objects seem the same, it is natural to suppose, if they are visually represented as having the same properties. Their being so represented does not preclude them from entering into the contents of the relevant experiences. Indeed, it seems that they must so enter in order for them to be represented at all.

This brings us back to the suggestion made earlier on behalf of the existential theorist that what is it for an object $O$ to look $F$ is for $O$ to cause (in the way involved in seeing $O$ ) an experience of an $F$. To accept this proposal is to be committed to denying that if $O$ looks $F$ then $O$ is visually experienced as being $F$. For $O$ cannot be experienced as being $F$ unless the relevant experience represents $O$ as $F$, assuming that experience is representational at all. But there seems to me a very strong intuitive pull to the thought that if $O$ looks $F, O$ is represented as $F$; and this is lost on the existential proposal.

Furthermore, there is a difficulty lurking for the above account by the existential theorist of what it is for $O$ to look $F$-a difficulty I have so far ignored. Suppose that I am seeing two objects, $a$ and $b$, such that $a$ looks red to me and $b$ looks green. The object, $a$, causes my experience of something green and it does so in the way involved in seeing $a$. But equally, so does $b$. In seeing both $a$ and $b$, I undergo an experience that represents something green, on the existential proposal. This experience, however, also represents something red. So, $b$ not only causes my experience of something red but it also causes my experience of something green, and it does so in the way involved in seeing $b$. So, $b$ looks red, but it also looks green. Clearly, something has gone wrong. The obvious diagnosis of the trouble is that the proposed account by the existential theorist of what it is for an object to look a certain way makes the mistake of removing the seen object from the content of the experience involved in seeing it. $^{26}$ 
A related thought counting against the existential view is that intuitively visual experiences have a singular phenomenology or at least a putatively singular phenomenology. They simply do not present the world to us in the way the existential thesis requires. There is a particularity in our experience which the existential thesis fails to capture fully.

The upshot, I suggest, is that the layer of existential content should be discarded. The best view to take, on balance, of the content of visual experience is the one offered by the singular (when filled) thesis. ${ }^{27}$ It follows from this that the argument from no common content is successful. Phenomenal character is not the same as representational content at all.

\section{A New Intentionalist Proposal}

Weak intentionalism is not threatened by the arguments presented in this essay. As noted earlier, weak intentionalism is a supervenience thesis. It asserts that necessarily, experiences with the same representational content have the same phenomenal character. However, weak intentionalism is a thesis that cries out for further development. Surely, it is not simply a brute fact that content determines phenomenal character. Some explanation is needed.

Consider then the singular content my experience has as I view a tomato and the corresponding gappy content your experience has as you hallucinate one. The contents are different but nonetheless they are of the same type. Each experience has a content that falls under the same SWF content schema. What the two experiences have in common, thus, is the possession of a content of a certain sort.

One way to capture this is to say that the two contents fall under an SWF content schema having a slot in it that is filled by an object in the one case but which is left empty in the other. Another way to put the point is to say that each experience has an SWF content into which all the same (non-object involving) properties enter. The obvious way, then, to begin to develop the weak intentionalist position further without its collapsing into strong intentionalism is to hold that the phenomenal character $P$ of a given token experience $E$ is a matter of $E$ 's having within its content a certain cluster of properties. ${ }^{28}$

In my view, for reasons elaborated elsewhere (Tye 1995, 2000), the relevant properties, in addition to being within E's content, should be nonconceptually represented and the content should be suitably poised to bring about cognitive responses. What emerges from these reflections, thus, is a form of intentionalism that bears the same sort of relationship to strong intentionalism as functionalism bears to the type identity theory. Just as functional properties are multiply physically realizable, so phenomenal properties, on this proposal, are multiple realizable via strong intentional properties of the sort strong intentionalism took to be identical with them. There is no one poised content which an experience must have in order to possess a given phenomenal character. Instead, 
its phenomenal character resides in its having $a$ poised content within which such-and-such a cluster of properties is nonconceptually repesented. We might call this view "second-order intentionalism." 29

One objection to this proposal is that it seems somewhat contrived. Can it really be that the phenomenal character of an experience is a second-order intentional property? However, in my view, the biggest difficulty this proposal faces is that does not do justice to the phenomenon of transparency. So, the attempt to identify phenomenal character with representational content or to find any intentional property, first or second-order, with which phenomenal character is identical seems to be in serious trouble.

The solution, in my view, is to take phenomenal character to be the cluster of properties within the content (singular or gappy). The property cluster gets to be the phenomenal character of a given visual experience, of course, only if it is represented by that experience (just as Benjamin Franklin gets to be the inventor of bifocals only if he invents bifocals). ${ }^{30}$ This view is developed in detail in forthcoming work. ${ }^{31}$

\section{Conclusion}

So, the Multiple Contents Thesis is to be rejected, as is the Existential Thesis. What remains is the Singular (When Filled) Thesis, and that is the thesis I embrace. The thesis is a form of disjunctivism in that it concedes that the content of visual experience in the hallucinatory case is different from the content of visual experience in the veridical case. At the level of content itself, there is indeed no common factor. For each experience, there is only a single admissible content, but this content is different in veridical and in hallucinatory cases. There is, however, in some such cases a common phenomenal character. This necessitates the rejection of strong intentionalism. But even though the argument from no common content succeeds, it leaves open another intentionalist view of phenomenal character-that of second-order intentionalism. ${ }^{32}$ Unfortunately, second-order intentionalism faces difficulties of its own. The solution is to look to the properties represented to find phenomenal character and not to the representing of those properties.

\section{Notes}

1. Not everyone accepts this claim. One notable exception is Travis (2004).

2. Not all disjunctivists grant that in cases of illusion, perceptual experiences have contents of the same sort as veridical perceptual experiences. See, e.g., Martin 2006. Obviously, those disjunctivists who take this view cannot use the present consideration to motivate their view.

3. Assuming that the term 'singular content' is used in the usual way. For an opposing usage, see Sainsbury 2006. 
4. This is an over-simplification. Martin, for example, sometimes seems to hold that there is "no distinctive mental event or state common to these various disjoint situations". (2004, p. 37) But he also says that "the disjunctive view itself should be viewed as strictly neutral between views which assume that experience is a common element and those that deny it". (1997, p. 86). In the text, I assume that disjunctivism is a definite metaphysical thesis. For more on varieties of disjunctivism, see Byrne and Logue, forthcoming.

5. Actually, it is a mistake to suppose that the soap and the lemon are not intrinsically the same. They are in that they have the same color and the same three-dimensional shape.

6. Strong intentionalism identifies phenomenal character with representational or intentional content that meets certain further conditions. For more on both strong and weak intentionalism, see the beginning of Section IV.

7. He also says in an earlier passage that we cannot deduce the identity of the object of an experience from knowledge of its content (1982, p. 38). McGinn's thought here may be that we can know the content of an experience via introspection without thereby knowing which object, if any, is present. However, this claim is open to dispute. If experiences have multiple contents (see here section VI below), it is not at all obvious that we can know each content via introspection. Further, even if experiences have only a single content, it could be held that what we can know via introspection is not the content but the phenomenal character.

8. Given the thesis of strong intentionalism together with the further claim that each perceptual experience has only a single representational content, the negative thesis that McGinn advocates in the quoted passage follows. But why make these assumptions? McGinn does not say.

9. The case that follows is similar to one Grice discusses in his 1961.

10. John Searle has a proposal along these lines in his 1983. In Searle's formulation, the content of my experience is that there is a yellow cube (ahead) and the fact that there is such a cube is causing this experience. This obviously won't do as it stands. Without some restrictions on the causal connection, it is easy to construct more complex mirror-case counter-examples.

11. I am indebted to Mark Sainsbury here.

12. Cp. Dretske 1995.

13. The problems do not end here. Veridical hallucinations cannot be handled on the causal version of the existential thesis. See here note 20 below and the surrounding discussion in the text.

14. Of course, the term 'content' is a term of art, and there is no one correct way to use it. As I use the term, the content of a thought is what is thought. It is expressed in the 'that'-clause and it is either true or false (or neither true nor false, on three-valued views).

15. Another possible view is that the thought is neither true nor false, since there is no object the thought is about either to have or to lack the attributed property. One difficulty for this view is that prima facie it requires us to give up the claim that the thought that this is a china frog is true if and only of this is a china frog in the second case.

16. Philosophers who emphasize the singularity or particularity of visual experience include Bach 1997, Soteriou 2000, and Sainsbury 2006. 
17. The seen object need not always be a common or garden manifest object such as a tomato.

18. This is not quite true. There are cases of de re hallucination, as, for example, when I dream with respect to my mother that she is being strangled by a snake. Here there is a particular - my mother - and so obviously the content of my visual experience (assuming it is agreed that dreams involve visual experiences) cannot be gappy. Such an experience is singular though the object involved is not seen. For taxonomical purposes, I am ignoring cases of this sort, but obviously they present no special difficulty for the singular (when filled) thesis.

19. Here is a worry for the Russellian view. Suppose that I hallucinate two yellow cubes and, on the basis of my experience, I believe that that is a yellow cube and that is a yellow cube too. What is the content of my experience? The content cannot be such that there is a single gap along with the property of being a yellow cube, nor can it be a conjunctive content having as each conjunct a gap along with the property of being a yellow cube. For given my experience I am entitled to infer from it that there are two yellow cubes (even though that is in fact not true).

One might respond that the content is conjunctive, having a gap and the property of being a yellow cube to the left of a yellow cube as its first conjunct and having a gap and the property of being a cube to the right of a yellow cube as its second conjunct. But this won't suffice to justify the inference to the conclusion that there are two yellow cubes (since one and the same thing could be to the left of a yellow cube and to the right of one as well).

An alternative reply along similar lines is to introduce directional properties into the conjunctive content. This seems to me to handle the problem satisfactorily.

20. Nor can the causal version of the existential thesis discussed in Section I. According to that thesis, there can be no such thing as a veridical hallucination, since when an hallucination is present, there is no object of the relevant sort in the scene before the subject's causing his or her experience. So, every hallucination must be counted as falsidical. This obviously won't do.

21. For more here, see Section VI below.

22. For a closely related alternative view, see Dretske 1995.

23. Sainsbury offers an example of this sort in his 2006, p. 254.

24. I return to this issue later.

25. For further discussion here leading to the same conclusion, see Schroeder and Caplan forthcoming.

26. I do not deny that further conditions could be imposed that would handle this objection. But these conditions would require that there be a sensitivity in the relevant part of the content of the token experience to the relevant object. Given such a sensitivity, it is no longer clear that the object has not been smuggled into the content after all.

27. Are there any visual experiences that do not have an $S W F$ content? Here is one possible case. Suppose that I am surrounded by a white mist. Arguably my experience in this instance has an existential content, since there is no seen object. Another view is that there is a seen object, namely the portion of the mist in my field of view, and the content is of the $S W F$ sort. 
What about the contents of experiences in the other sensory modalities? Again, I am inclined to favor the singular (when filled) thesis. In the case of auditory experience, for example, the relevant particular (if there is one) is a particular sound. Things are heard by hearing the sounds they emit and sounds are particulars. Similarly, in the case of olfactory experience, the particular are smells. We smell things by smelling the odors they produce and odors are particulars. Odors begin and end. They have spatio-temporal locations, even if these locations are not at all precise.

28. It might seem that this view cannot distinguish the case of hallucinating a red square and a green triangle from that of hallucinating a green square and a red triangle, since each experience represents the same color and shape properties: greenness, triangularity, redness, and squareness. This forgets that there are other properties represented by each experience too. In the former case, the property of being a red square is represented; not so in the latter. In the latter case, the property of being a green square is represented; not so in the former.

29. The usual arguments for intentionalism go through for second-order intentionalism. For a summary of these arguments, see Tye forthcoming a.

30. The properties in the cluster can be uninstantiated. Some philosophers take this to be problematic; but it is part and parcel of commonsense. If one hallucinates a pink elephant, pink is present to one's consciousness. On the basis of one's experience of pink, one can know what it is like to experience pink. Further veridical experience is not needed.

31. See here Tye forthcoming b.

32. I would like to thank Alex Byrne, Tim Crane and Susannah Siegel for helpful discussion. An earlier version of this essay formed the basis for a talk at U.N.A.M. in Mexico City. I thank members of that audience for their comments.

\section{References}

Austin, J.L. 1962. Sense and Sensibilia. Oxford: Clarendon Press.

Bach, K. 1997. "Searle Against the World." Unpublished ms. Available at http://online. sfsu.edu/k̃bach/Searle.html.

Block, N. 1990. "Inverted earth." Philosophical Perspectives 4: 53-79.

Byrne, A. 2001. "Intentionalism Defended." Philosophical Review 110: 49-90.

Byrne, A. and H. Logue. forthcoming. "Either/Or: Disjunctivism for Dummies.", in Disjunctivism: Perception, Action, Knowledge, A. Haddock and F. Machpherson, eds. Oxford: Oxford University Press.

Davies, M. 1992. "Perceptual Content and Local Supervenience." Proceedings of the Aristotelian Society 92: 21-45.

Drestke, F. 1995. Naturalizing the Mind. Cambridge, MA: MIT Press.

Grice, H. P. 1961. "The Causal Theory of Perception." Proceedings of the Aristotelian Society, Supplementary Volume 35: 121-52. Selection reprinted in Perceptual Knowledge, J. Dancy, ed. (Oxford: Oxford University Press, 1998).

Hinton, J. M. 1973. Experiences. Oxford: Clarendon Press.

Jackson, F. 2003. "Mind and Illusion" in Minds and Persons, A. O'Hear, ed. Cambridge: Cambridge University Press, pp. 251-271.

Kaplan, D. 1989. "Demonstratives" and "Afterthoughts" in Themes from Kaplan, J. Almog, J. Perry, \& H. Wettstein, eds. New York: Oxford University Press. 
Lewis, D. 1980. "Veridical Hallucination and Prosthetic Vision". Australasian Journal of Philosophy 58: 239-49.

Lycan, W. 1996. Consciousness and Experience. Cambridge, MA: MIT Press.

Martin, C. B. 1994. "Dispositions and Conditionals". Philosophical Quarterly 44: 1-8.

Martin, M. 1997. "The Reality of Appearances" in Thought and Ontology, M. Sainsbury, ed. Milan: Franco/Angeli, pp. 81-106.

Martin, M. 2002. "The Transparency of Experience". Mind \& Language, 17: 376-425.

Martin, M. 2006 "On Being Alienated." in Perceptual Experience, T. Gendler and J. Hawthorne, eds. Oxford: Oxford University Press, pp. 354-410.

McGinn, C. 1982. The Character of Mind. Oxford: Oxford University Press.

Millar, A. 1991. Reasons and Experiences. Oxford: Clarendon Press.

Moore, G. E. 1903. "The Refutation of Idealism" in his Philosophical Papers.

Price, H. H. 1932. Perception. London: Methuen.

Sainsbury, M. 2006. Reference without Referents. Oxford: Oxford University Press.

Schroeder, T. and Caplan, B. forthcoming. "On the Content of Experience". Philosophy and Phenomenological Research.

Searle, J. 1983. Intentionality. Oxford: Clarendon Press.

Snowdon, P. 1990. "The Objects of Direct Experience". Proceedings of the Aristotelian Society, Supplementary Volume 64: 121-150.

Soteriou, M. 2000. "The Particularity of Visual Perception". European Journal of Philosophy 8: $173-189$.

Travis, C. 2004. "The Silence of the Senses". Mind 113: 57-94.

Tye, M. 1995. Ten Problems of Consciousness. Cambridge, MA: MIT Press.

Tye, M. 2000. Consciousness, Color, and Content. Cambridge, MA: MIT Press.

Tye, M. Forthcoming a. "Representationalist Theories of Consciousness" in B. McLaughlin and A. Beckermann, eds. Oxford Handbook of the Philosophy of Mind. Oxford: OUP.

Tye, M. Forthcoming b. Materialism without Phenomenal Concepts: A New Perspective on the Major Puzzles of Consciousness. Cambridge, MA: MIT Press. 